\title{
Synthesis and characterization of chitosan-silver nanocomposite
}

\author{
S. Govindan · E. A. K. Nivethaa • R. Saravanan • \\ V. Narayanan $\cdot$ A. Stephen
}

Received: 30 November 2011/ Accepted: 26 March 2012/Published online: 5 May 2012

(C) The Author(s) 2012. This article is published with open access at Springerlink.com

\begin{abstract}
Chitosan-silver (CS-Ag) nanocomposite materials were synthesized by a simple chemical method. The synthesized CS-Ag nanocomposite contains $20 \mathrm{wt} \%$ silver. Silver nanoparticles were synthesized by chemical reduction method as well. The CS-Ag nanocomposite was characterized using Field emission scanning electronic microscope (FESEM), X-ray diffraction (XRD) and Fourier transform infrared spectroscopy (FTIR). The XRD pattern indicated the presence of both silver and chitosan in the nanocomposite. It is observed from the XRD pattern of silver that it is of cubic structure. The spherical morphology of silver nanoparticles was confirmed from the FESEM image. FTIR spectroscopy was used for the structural elucidation. CS-Ag nanocomposite exhibits good antimicrobial and antitumor properties.
\end{abstract}

Keywords Nanocomposite - Biocompatible $\cdot$ Chitosan · Silver

\section{Introduction}

There has been a tremendous increase in the number of patients affected by diseases like diabetes and cancer during the last decade. So, it has become the major focus of researchers to synthesize a compound that will be useful

S. Govindan · E. A. K. Nivethaa - R. Saravanan .

A. Stephen $(\bowtie)$

Department of Nuclear Physics, Material Science Centre, University of Madras, Guindy Campus, Chennai 600 025, India e-mail: stephen_arum@hotmail.com

V. Narayanan

Department of Inorganic Chemistry, University of Madras, Guindy Campus, Chennai 600 025, India for the monitoring of certain elements that are present in excess quantities in the blood while used in the form of biosensors, at the same time being useful for the treatment of diseases like cancer.

Chitosan (CS) is a polysaccharide composed of glucosamine and $N$-acetyl glucosamine linked with a $\beta-1-4-$ glycosidic linkage (Crini et al. 2008). CS is a biopolymer which is biocompatible and can be degraded by enzymes in human body, the degradation products are nontoxic. Commercial CS's are semi-crystalline polymers and crystallinity plays an important role in adsorption efficiency (Trung et al. 2006). CS is a polymer which exhibits a broad spectrum of antimicrobial activity by binding to the negatively charged bacterial cell wall followed by attachment to the DNA, inhibiting its replication. CS is a biopolymer having antibacterial properties (Kurita et al. 1993; Ting and Shen 2005). For the improvement of bioactivity on chitosan, it is often combined to other bioactive materials, such as drugs.

Silver (Ag) nanoparticles have high therapeutic potential and exhibit good antimicrobial activity. Ag nanoparticles have a wide range of antimicrobial activities and exhibit high performance even at a very low concentration. $\mathrm{Ag}$ nanoparticles have been identified to possess good potential for the treatment of cancer (Sriram et al. 2010). But the major disadvantage of using silver alone is that it is not specific at targeting the cancer cells and also it is toxic to the normal cells when exposed for a longer time when the size of silver used is $>20 \mathrm{~nm}$ (Vaidyanathan et al. 2009)

$\mathrm{CS}-\mathrm{Ag}$ nanocomposite is one of the rare composite materials that is seen to possess a capability of being used as a biosensor as well as in the treatment of cancer as the chitosan present in the nanocomposite is very specific to the cancer cells. It prolongs the action of silver on the affected cells while preventing the normal cell from the 
effect of silver. One more advantage of this nanocomposite is that it is biodegradable, i.e., it can be degraded by the enzymes present in the body making it suitable for the treatment of cancer. Apart from the treatment of cancer, the nanocomposite also possesses good antimicrobial (Sanpui et al. 2008) and biosensing activity.

In this work, CS-Ag nanocomposite was synthesized by the chemical method with $20 \mathrm{wt} \% \mathrm{Ag}$. CS-Ag was successfully synthesized and characterized with Fourier transform infrared spectroscopy (FTIR), X-ray diffraction analysis (XRD) and field emission scanning electron microscopy (FESEM).

\section{Experimental}

Materials

Chitosan (medium molecular weight), silver nitrate were purchased from Sigma-Aldrich. Sodium borohydride, sodium citrate sodium sulphate and acetic acid were of SRL grade.

Synthesis

The chemical method was used for the synthesis of chitosan, silver and chitosan-Silver nanocomposite. Chitosan $(0.25 \mathrm{~g})$ was dissolved in $2 \%$ acetic acid, while stirring followed by sonication for $15 \mathrm{~min}$. This was then filtered to obtain a clear solution. $20 \% \mathrm{Na}_{2} \mathrm{SO}_{4}$ was then added drop wise to the aq. chitosan solution, which was simultaneously stirred and sonicated. The solution was left undisturbed, centrifuged at $8,000 \mathrm{rpm}$ to collect the CS nanoparticles (Baek et al. 2008). Silver nanoparticles were obtained by dissolving $0.4225 \mathrm{~g}$ of $\mathrm{AgNO}_{3}$ in water and stirring for about $20 \mathrm{~min}$. To this sodium citrate solution (73.5 g) was added. $\mathrm{NaBH}_{4}$ solution (1.318 g) was added drop wise to the above solution and stirred. Sodium citrate was used as a stabilizing or capping agent to prevent the aggregation of nanoparticles and to control the size of the nanoparticles, while sodium borohydride was used as a reducing agent (Tolaymat et al. 2010). The settled particles were collected by filtration.

For the synthesis of CS-Ag nanocomposite, $0.5 \mathrm{~g}$ of chitosan was dissolved in $2 \%$ acetic acid, to which $1 \%$ PVA solution was added. $20 \% \mathrm{Na}_{2} \mathrm{SO}_{4}$ solution was added drop wise to the above solution under simultaneous stirring and sonication. $0.1 \mathrm{~g}$ of synthesized silver accounting for $20 \mathrm{wt} \%$ was added to the solution which was stirred under sonication for ample time. $20 \mathrm{wt} \%$ indicates that the amount of silver taken for the preparation of the nanocomposite amounts to $20 \%$ of the weight of chitosan used. The calculation is as shown below.
Table 1 Examples for the calculation of weight percentage of silver

\begin{tabular}{lllr}
\hline S. no. & $\begin{array}{l}\text { Amount of } \\
\text { chitosan taken }(\mathrm{g})\end{array}$ & $\begin{array}{l}\text { Amount of } \\
\text { silver taken }(\mathrm{g})\end{array}$ & wt\% \\
\hline 1 & 0.5 & 0.025 & 5 \\
2 & 0.5 & 0.05 & 10 \\
3 & 0.5 & 0.075 & 15 \\
4 & 0.5 & 0.1 & 20 \\
\hline
\end{tabular}

$\left(\frac{0.1}{0.5}\right) \times 100 \%=20 \%$.

A table (Table 1) showing the calculation of weight percentage of Silver is shown below. The solution was then centrifuged at 8,000 rpm for $20 \mathrm{~min}$ after which particles were collected and dried at room temperature.

$\mathrm{CS}-\mathrm{Ag}$ nanocomposites containing various amounts of silver like 5, 10, 15 and $20 \mathrm{wt} \%$ were synthesized. Of these the composite containing $20 \mathrm{wt} \%$ of silver is chosen here for discussions as the properties of silver will be more pronounced when the amount of silver present in the composite is more. So it would be easier for us to study the properties of silver as well chitosan.

\section{Particle characterization}

The structure analysis of the prepared samples was done using a Rich Siefert 3000 XRD meter using $\mathrm{Cu} \mathrm{K} \alpha_{1}$ radiation $(\lambda=1.5406 \AA$ ), surface morphology of $\mathrm{CS}-\mathrm{Ag}$ nanocomposite was observed using a HITACHI-SU 6600 FESEM. Functional group confirmations were assessed by SHIMADZU IR-affinity FTIR spectrometer.

\section{Results and discussion}

The structural properties of the synthesized CS-Ag nanocomposite were analyzed using the XRD technique. The obtained XRD pattern for chitosan is shown in Fig. 1. The peaks appeared at $2 \theta$ values of $11.7^{\circ}$ and $20.2^{\circ}$ which match well with the literature values (Harish Prashanth et al. 2002; Wang et al. 2004; Kong et al. 2005). The broadening of the peaks is due to the amorphous nature of the polymer (Rhim et al. 2006). There is no impurity peaks observed in the XRD pattern.

The XRD pattern of silver is shown in Fig. 2 which clearly indicates the formation of silver in a single phase. Peaks were obtained at $2 \theta$ values of $37.9^{\circ}, 44.0^{\circ}$ and $63.9^{\circ}$ which are in perfect agreement to that of the JCPDS card no. 89-3722 (Raffi et al. 2008). Peak fitting was done for the obtained pattern, the crystal structure was found to be simple cubic and the lattice parameters was determined to 


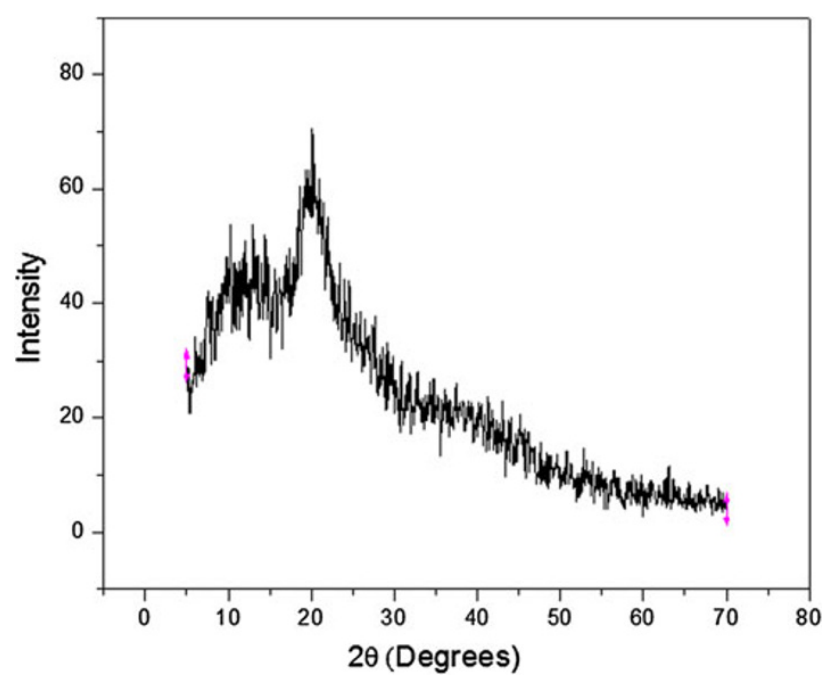

Fig. 1 XRD pattern of chitosan

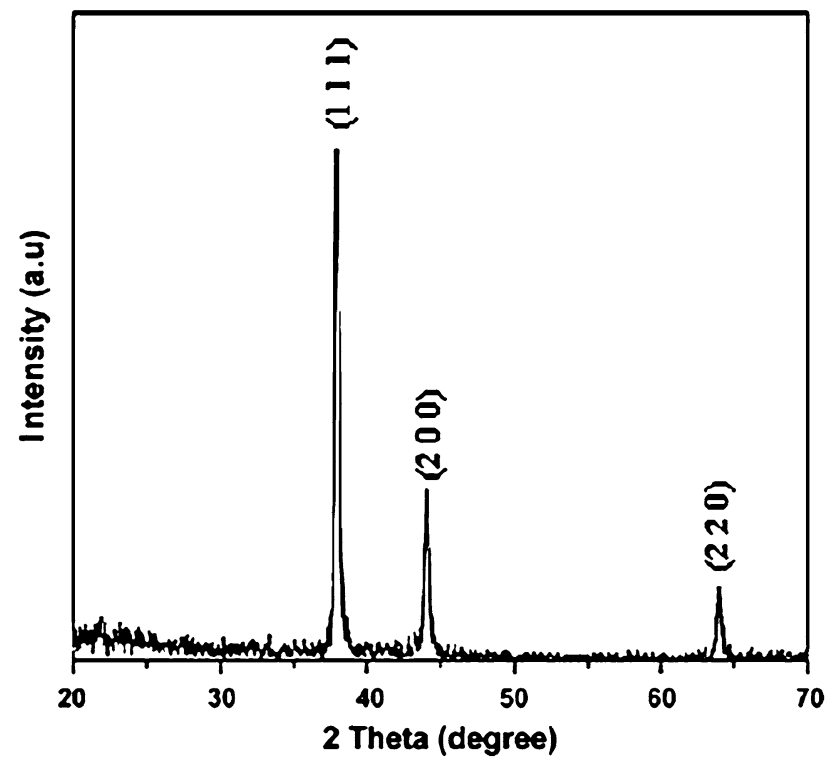

Fig. 2 XRD pattern of silver

be ' $a$ ' $=4.111 \AA$. The $(h k l)$ values are indicated in the Fig. 2. The average crystallite size of the silver nanoparticles calculated using the Scherrer formula was $23 \mathrm{~nm}$.

The presence of chitosan as well as silver peaks is observed from the XRD pattern of CS-Ag nanocomposite which is shown in Fig. 3. This seems to be in agreement with the values reported in the literature (Rhim et al. 2006). The chitosan peaks are represented using arrows, while the silver peaks are designated with their $(h k l)$ values. The regions of the graph at which the chitosan peaks appear are separately represented in an inset. The CS peaks were obtained at $2 \theta$ values of $11.7^{\circ}, 19.8^{\circ}$ and silver peaks were obtained at $37.9^{\circ}, 44.0^{\circ}$ and $63.9^{\circ}$, respectively.

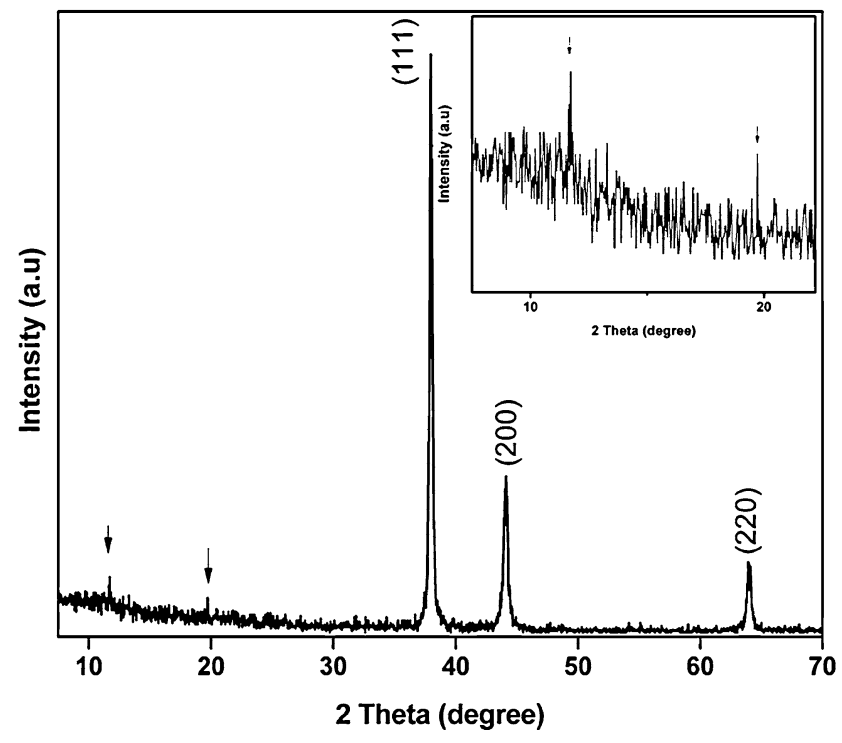

Fig. 3 XRD pattern of chitosan-silver nanocomposite

The surface morphology of synthesized CS-Ag nanocomposite was analyzed using the FESEM technique. The FESEM image of CS shows that the particles are in the form of bundles with a leaf morphology (Fig. 4). The FESEM image of silver nanoparticles shows spherical shaped particles (Fig. 5) (Cynthia Jemima Swarnavalli et al. 2011). The size of the particles is seen to be almost uniform. The FESEM image (Fig. 6) of CS-Ag nanocomposite shows a mixture of $\mathrm{CS}$ and $\mathrm{Ag}$ wherein the silver nanoparticles are seen to be enveloped by the chitosan polymer (Yoshizuka et al. 2000). The synthesized particles are in the form of aggregates. Prepared nanoparticles show low dispersibility and high stability. The reduction of agglomeration is seen to occur when the chitosan is allowed to dissolve for a longer duration of time, followed by the dispersion of silver nanoparticles in the chitosan solution for about an hour before the process of reduction. The FESEM image of such a well dispersed and stabilized synthesized composite is shown in Fig. 7. It is observed that the silver nanoparticles are embedded in a matrix of chitosan and also that the size of the composite is confined to the nano range.

The FTIR spectrum (Fig. 8) of the silver nanoparticles shows O-H stretching at 3,441 and $2,929 \mathrm{~cm}^{-1}$ and $\mathrm{N}-\mathrm{H}$ bending at $1,639 \mathrm{~cm}^{-1}$, this is in agreement with the FTIR results of Mallikarjuna et al. (2011). The FTIR spectrum of chitosan shows $\mathrm{O}-\mathrm{H}$ stretching at $3,433 \mathrm{~cm}^{-1}, \mathrm{C}-\mathrm{H}$ and $\mathrm{C}-\mathrm{N}$ stretching at $2,920 \mathrm{~cm}^{-1}, \mathrm{~N}-\mathrm{H}$ bending at $1,647 \mathrm{~cm}^{-1}$, $\mathrm{N}-\mathrm{H}$ angular deformation in $\mathrm{CO} \mathrm{NH}$ plane at $1,536 \mathrm{~cm}^{-1}$ and $\mathrm{C}-\mathrm{O}-\mathrm{C}$ band stretching at $1,109 \mathrm{~cm}^{-1}$ which matches well with the report by Saraswathy et al. (2001) and Wazed Ali et al. (2001). In the FTIR spectrum of CS-Ag nanocomposite, the shifting of the CS peaks is observed which 


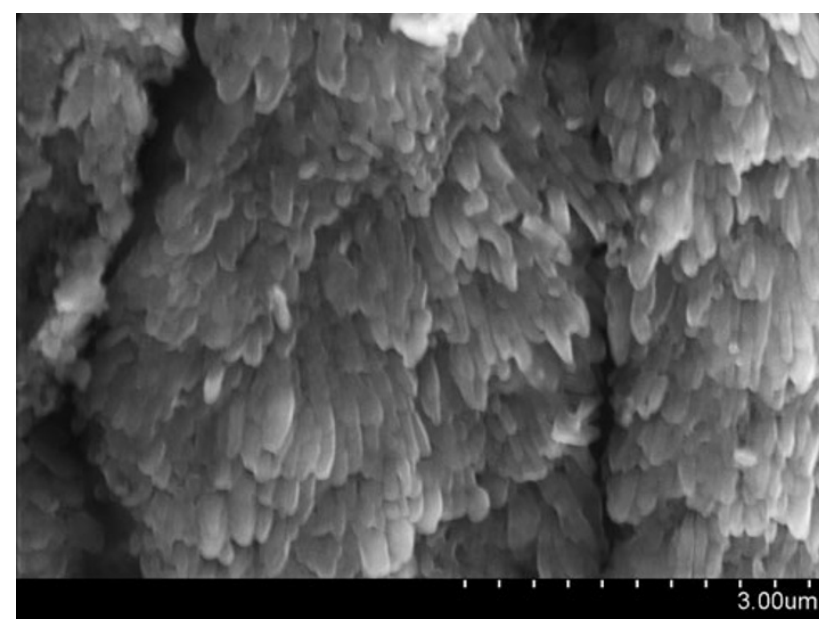

Fig. 4 FESEM image of chitosan

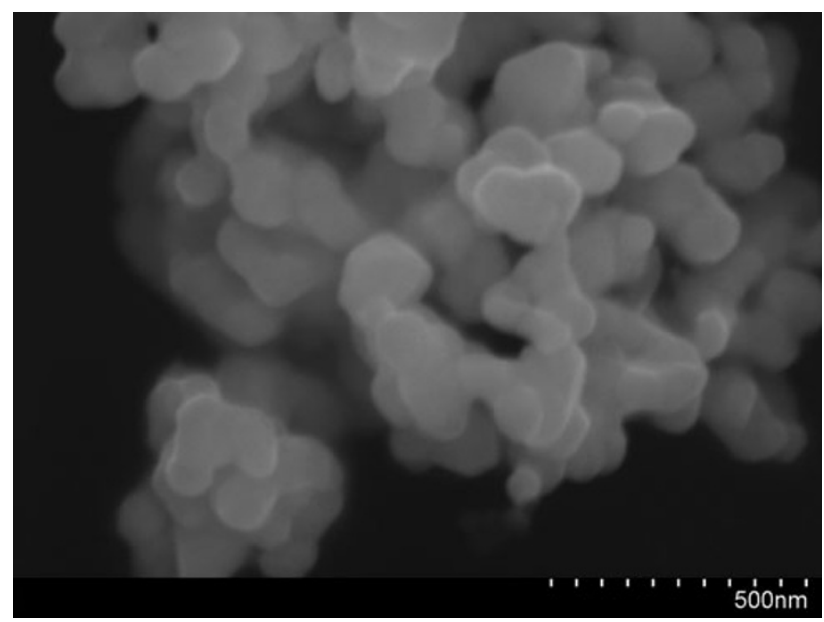

Fig. 5 FESEM image of silver nanoparticles

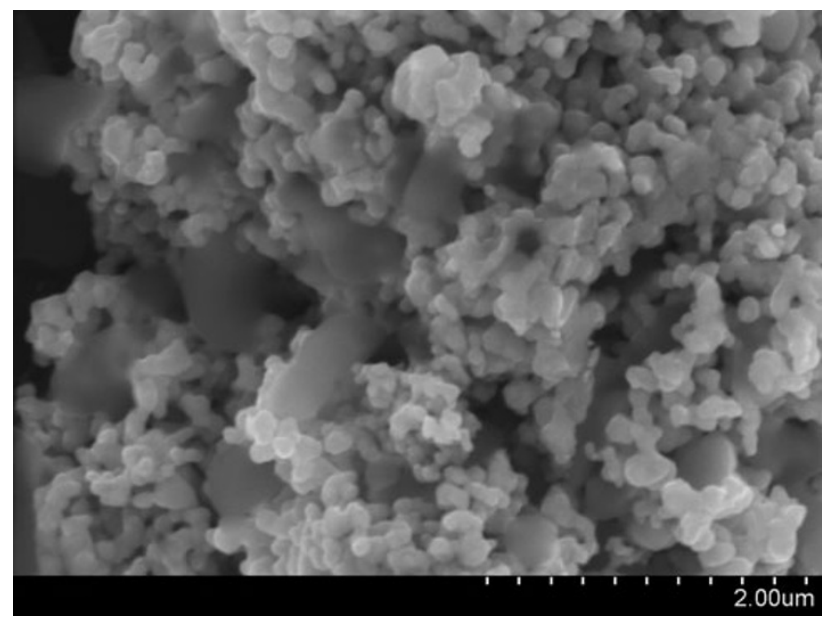

Fig. 6 FESEM image chitosan-silver nanocomposite

may be due to the interaction of Ag with $\mathrm{CS}$ in the nanocomposite. The other changes that are noticeable are the reduction in the intensity of the hydroxyl peak and the

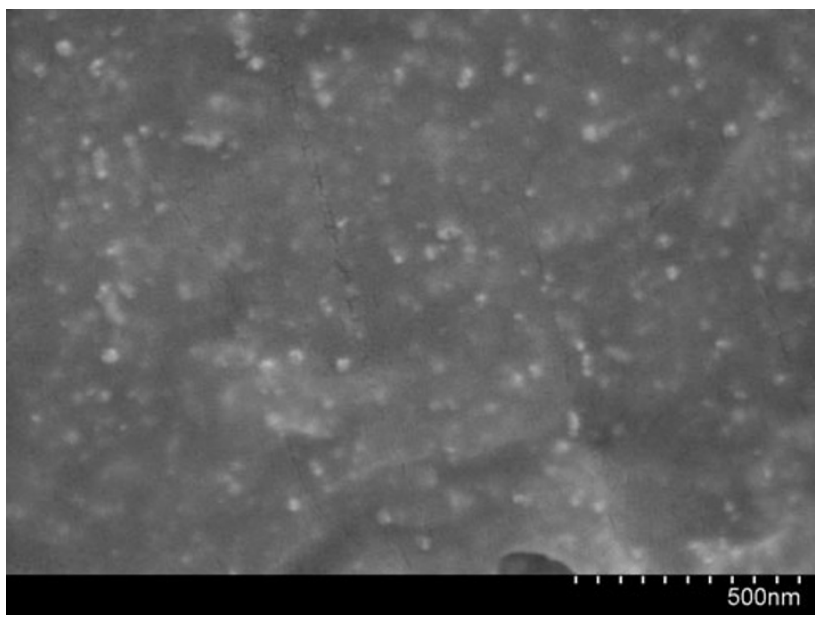

Fig. 7 FESEM image of synthesized chitosan-silver nanocomposite exhibiting high dispersibility and stability

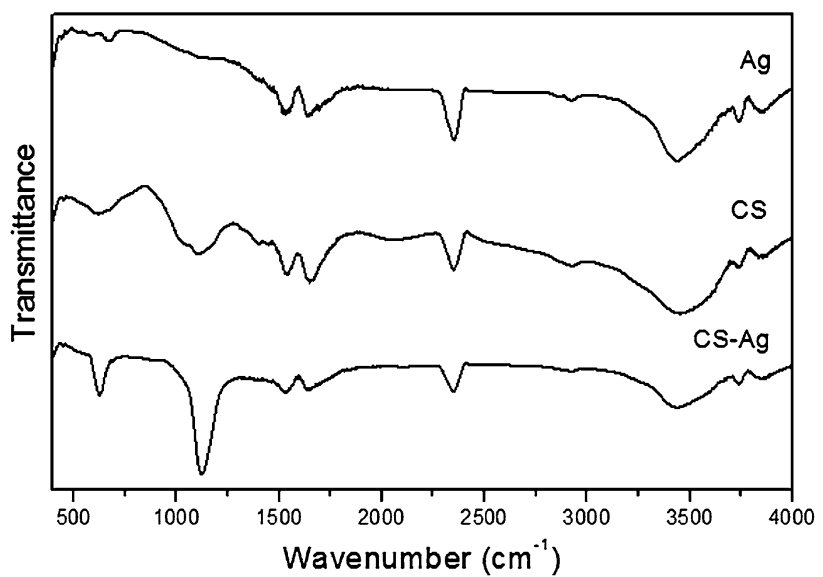

Fig. 8 FTIR spectrum of silver (Ag) nanoparticles, chitosan (CS), chitosan-silver (CS-Ag) nanocomposite

increase in the intensity of the $\mathrm{C}-\mathrm{O}$ stretching which are in agreement with the FTIR results of Gupta et al. (2008) and An et al. (2011).

\section{Conclusions}

Chitosan, silver nanoparticles and chitosan-silver nanocomposite was synthesized using simple chemical method. The XRD patterns of CS, Ag and CS-Ag are seen to be free from impurity peaks and the respective XRD patterns indicate the formation of $\mathrm{Cs}, \mathrm{Ag}$ and $\mathrm{CS}-\mathrm{Ag}$ nanocomposite clearly. The FESEM image of $\mathrm{Ag}$ indicates the formation of spherical nanoparticles which are of uniform size. The FESEM image of CS shows the formation of CS in the form of bundles. IN the FESEM image of the CS-Ag nanocomposite the silver nanoparticles are seen to be enveloped by CS, and agglomeration is also observed. It is 
evident that agglomeration can be prevented on dispersing $\mathrm{Ag}$ in CS for a longer duration of time. The FESEM pattern obtained for the samples after sufficient dispersion shows the silver nanoparticles to be embedded in a matrix of CS. The shift in the peaks of CS observed in the FTIR spectrum indicates the formation of $\mathrm{CS}-\mathrm{Ag}$ composite. It is evident from all the Characterizations done that the CS-Ag nanocomposites have been prepared successfully.

Acknowledgments We acknowledge The National Centre for Nanoscience and Nanotechnology, University of Madras, India for FESEM studies.

Open Access This article is distributed under the terms of the Creative Commons Attribution License which permits any use, distribution, and reproduction in any medium, provided the original author(s) and the source are credited.

\section{References}

An J, Luo Q, Yuan X, Wang D, Li X (2011) Preparation and characterization of silver-chitosan nanocomposite particles with antimicrobial activity. J Appl Polym Sci 120:3180-3189

Baek S-H, Kim B, Suh K-D (2008) Chitosan particle/multiwall carbon nanotube composites by electrostatic interactions. Colloids Surf A 316:292-296

Crini G, Badot P-M (2008) Application of chitosan, a natural aminopolysaccharide, for dye removal from aqueous solutions by adsorption processes using batch studies. A review of recent literature. Prog Polym Sci 33:399-447

Cynthia Jemima Swarnavalli G, Joseph V, Kannappan V, Roopsingh D (2011) A simple approach to the synthesis of hexagonalshaped silver nanoplates. J Nanomater. ID 825637; doi:10.1155/ 2011/825637

Gupta P, Bajpai M, Bajpai SK (2008) Investigation of antibacterial properties of silver nanoparticle-loaded poly (acrylamide-coitaconic acid)-grafted cotton fabric. J Cotton Sci 12:280-286

Harish Prashanth KV, Kittur FS, Tharanathan RN (2002) Solid state structure of chitosan prepared under different $\mathrm{N}$-deacetylating conditions. Carbohydr Polym 50:27-33

Kong L, Gao Y, Cao W, Gong Y, Zhao N, Zhang X (2005) Preparation and characterization of nano-hydroxyapatite/chitosan composite. J Biomed Mater Res, Part A 75A:275-282
Kurita K, Tomita K, Tada T, Nishimura SL, Ishii S (1993) Reactivity characteristics of a new form of chitosan. Polym Bull 30:429-433

Mallikarjuna K, Narasimha G, Dillip GR, Praveen B, Shreedhar B, Sree Lakshmi C, Reddy BVS, Deva Prasad Raju B (2011) Green synthesis of silver nanoparticles using ocimum leaf extract and their characterization. Digest J Nanomater Biostruct 6:181-186

Raffi M, Hussain F, Bhatti TM, Akhter JI, Hameed A, Hasan MM (2008) Antibacterial characterization of silver nanoparticles against E. coli ATCC-15224. J Mater Sci Technol 24(2):192-196

Rhim J-W, Hong S-I, Park H-M, Perry Ng KW (2006) Preparation and characterization of chitosan-based nanocomposite films with antimicrobial activity. J Agric Food Chem 54:5814-5822

Sanpui P, Murugadoss A, Durga Prasad PV, Ghosh SS, Chattopadhyaya A (2008) The antibacterial properties of a novel chitosan-Ag nanoparticle composite. Int J Food Microbiol 124: $142-146$

Saraswathy G, Pal S, Rose C, Sastry TP (2001) A novel bio-inorganic bone implant containing deglued bone, chitosan and gelatin. Bull Mater Sci 24:415-420

Sriram MI et al (2010) Antitumor of silver nanoparticles in Dalton's lymphoma ascites tumor model. Int J Nanomed 5:753-762

Ting DR, Shen Y (2005) Antibacterial finishing with chitosan derivatives and their nano-particles. Dyeing Finishing 14:12-14

Tolaymat TM, El Badawy AM, Ash G, Scheckel KG, Luxton TP, Suidan M (2010) An evidence-based environmental perspective of manufactured silver nanoparticles in syntheses and application: a systematic review and critical appraisal. Sci Total Environ 408:999-1006

Trung TS, Thein-Han WW, Qui NT, Ng C-H, Stevens WF (2006) Functional characteristics of shrimp chitosan and its membranes as affected by the degree of deacetylation. Bioresour Technol 97:659-663

Vaidyanathan R, Kalishwaralal K, Gopalram S, Gurunathan S (2009) Nanosilver-the burgeoning therapeutic molecule and its green synthesis. Biotechnol Adv 27:924-937

Wang X, Du Y, Liu H (2004) Preparation, characterization and antimicrobial activity of chitosan-Zn complex. Carbohydr Polym 56:21-26

Wazed Ali S, Rajendran S, Joshi M (2001) Synthesis and characterization of chitosan and silver loaded chitosan nanoparticles for bioactive polyester. Carbohydr Polym 83:438-446

Yoshizuka K, Lou Z, Inoue K (2000) Silver-complexed chitosan microparticles for pesticide removal. React Funct Polym 44:47-54 